\title{
RESOURCE SHARING TECHNOLOGY IN THE AUTOMOBILE PARTS MANUFACTURE GRID
}

\author{
Yufeng Ding ${ }^{1,2}$, Zhongling Wei ${ }^{1}$, Buyun Sheng ${ }^{1,2}$ \\ ${ }^{1}$ School of Mechanical and Electrical Engineering; Email: dingyf@mail.whut.edu.cn; ${ }^{2} \mathrm{Hubei}$ \\ Province Digit Manufacturing Key Laboratory, Wuhan University of technology, P.R. China.
}

\begin{abstract}
The manufacture resource classification model is described by using UML class graph in the manufacture grid system of automobile parts industry. Manufacture grid service system structure and resource agent structure is put forward. Manufacture resource attribute is defined using XML standard and the unification standard is provided for manufacture resources description using manufacture resources semantics dictionary. Referencing the manufacture resources semantics dictionary interface naming standard, manufacture resource service interface is described by using WSDL standard. A manufacture resource grid service prototype system is developed on the basis of GT3 development toolkit on the Windows platform, at last the product development process is described in the manufacture grid system by regarding automobile steering product as instance.
\end{abstract}

Key words: Manufacture grid, Resource sharing, XML, WSDL, PDM.

\section{INTRODUCTION}

Grid referring to a group of sharing resource integration, also called super virtual computer, is a technology which connect wide-area distributed computer resources by internet or special-purpose network. Ian Foster puts forward the most influential definition of grid in 2001: Dynamic multimechanism virtual organization resource sharing and cooperating problemsolved ${ }^{1,2}$.From this definition we can see that manufacture grid has three characters : resource sharing, cooperating and dynamic forming virtual organization. At present many domestic and foreign companies and national development facilities have studied the grid technology penetratingly, BOEING, FORD, BMW and other big companies are all attempting to apply

This paper is supported by Hubei province digital manufacturing key lab opening fund project (SZ0406), National Natural Science Foundation of China (50335020) and Wuhan science and technology key plan (20055102021).

Please use the following format when citing this chapter:

Ding, Yufeng, Wei, Zhongling, Sheng, Buyun, 2006, in International Federation for Information Processing (IFIP), Volume 207, Knowledge Enterprise: Intelligent Strategies In Product Design, Manufacturing, and Management, eds. K. Wang, Kovacs G., Wozny M., Fang M., (Boston: Springer), pp. 853-862. 
grid computation to the design and simulation of complex products, emphasis on solving the multitude computation problem of complex products such as airplane, automobile products. Ford company built a network bazaar by using grid technology, through which Ford can connect with more than 30,000 Suppliers.

The application of grid technology in manufacture field is just initial stage, manufacture grid which integrated design resources, manufacture resources and flow information in the product life cycle, is the development platform and supporting environment of modern integration manufacture system. The manufacture grid provide enterprises with integrated support service platform for application development and the system function, the platform is open, easy to maintain, and can be reconstructed in the process of enterprise's implementing advancing manufacture technology. The application of grid technology can provide a public manufacture grid platform for the manufacturing industry, can realize resources sharing, cooperating design and cooperating manufacture, so as to achieve the purpose of reducing the production cost, raising the resources utility and speeding up product's going onto market. The existing manufacture resources sharing plan, such as the Internet,B2B,ASP,Java,CORBA and so on, can not satisfy the virtual organization need completely ${ }^{3}$. The superiority of grid technology is to solve the problem of resources sharing and cooperating work among dynamic virtual organizations. Zhou Guanghui et al. proposed resource encapsulation and integration platform and frame ${ }^{4}$. Yang Jingquan et al. studied non-interaction computation resources issuing automatic encapsulation tool $1^{5}$. Because manufacture resources are so many that constructing manufacture grid facing all manufacturing industries products is not realistic. It is possible to build an industry manufacture grid to solve resource sharing problem.

\section{AUTOMOBILE PARTS MANUFACTURE GRID SERVICE SYSTEM STRUCTURE}

\subsection{Manufacture resources classification}

The manufacture resource includes enterprise equipment, material, staff and the total sum of the hardware and the software of product life cycle involving. The human resources are the industry experts which have the different special skills live in different regions. The on-line experts carry out the product design and make production preparation information by using the sharing tool (CAD/ CAPP /CAM /CAE and so on), then save product information to the resource database. The equipment resources and special 

Grid

technologies include the numerical control machine, the processing center, the special processing equipment (for example nanometer ultra precisely process machine, laser processing machine, rapid prototype manufacture, digitized scanner, casting machine) and so on in the manufacture network. For grid system the most important task is how to select manufacture equipment and processing enterprise can be used in the different regions, it is decided by the product manufacture information and other factors. The last processing enterprises are determined by competing or assigning mode within all selectable enterprise. The corresponding production preparation information is got from network in the resources database by matching the part number and attribute information. The part can be further revised and consummated for procedure, the data, the cutting instrument and the measuring instrument information until the product processing completion based on the network. In the manufacture grid, manufacture resources can be divided into nine classifications according to the resources attribute(physical characteristic, geographical position, dynamics characteristic, sensitivity, function and so on), the customer demand (time, quality, price, service and so on), used way (discovery, proxy, monitor, diagnosis and so on), manufacture resources is described by UML class graph is shown in Figure 1.

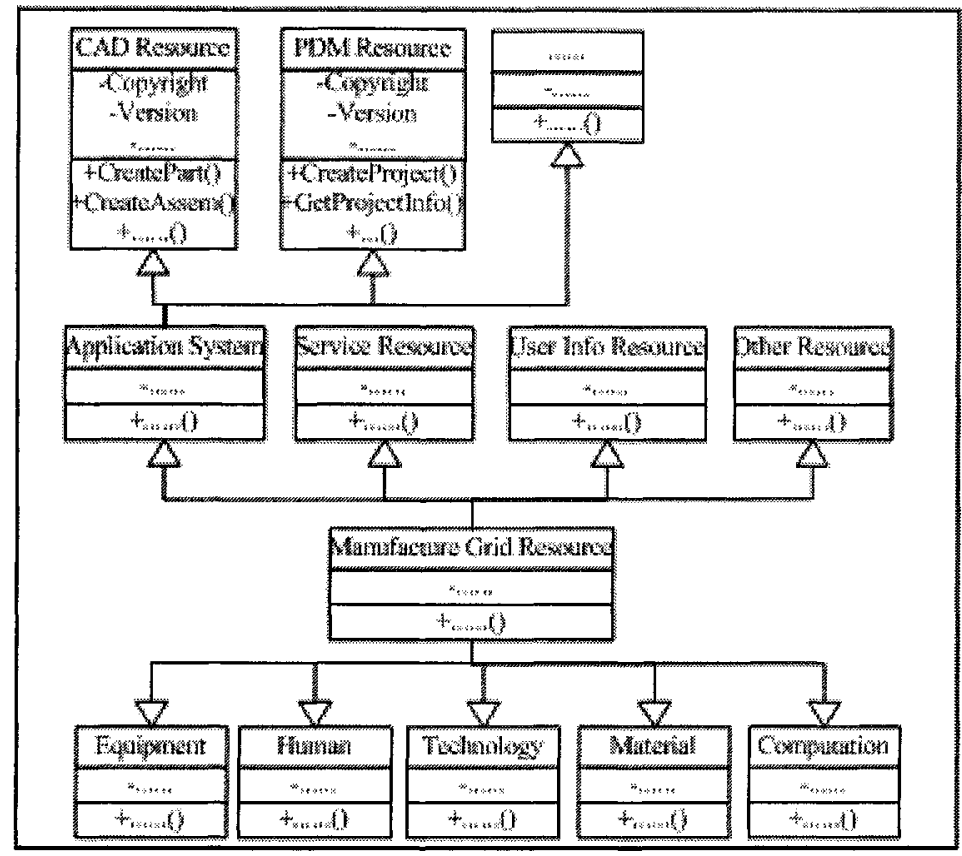

Figure 1. Manufacture resource UML class graph 


\subsection{Automobile parts industry manufacture grid service system structure}

It needs to build up a register service and a handle mapping service in order to share resource in the manufacture grid. Manufacture resources can be encapsulated into services and the service can be issued into grid UDDI

(Universal Description and Integration) registered center which may offer registering service. Manufacture grid user may visit registered center through resource agent so as to get all registered information of manufacture resources service factory and the existing service instance information. The user (include resource supplier and resource user) can create an instance by making a request from specified service factory, and send the data to the instance according to service interface standard. Then the user may visit manufacture grid service instance and use the function which the service offers. The process is shown as Figure 2. Resource description is the precondition of building manufacture grid and realizing resource sharing. When a manufacture resource supplier joins manufacture grid, manufacture grid will record resource function, using interface, period of validity and safe coefficient etc. When resource user needs to use a resource, they need put forward a clear function description, and then the resource agent of manufacture grid may seek suitable manufacture according to the user need. It has four kinds of major data type in UDDI registered center. They are BusinessEntity, businessService, bindingTemplate and tModel. To help to issue and seek WSDL service description in UDDI registered center, WSDL document has been divided into two types: Service interface and service implementation.

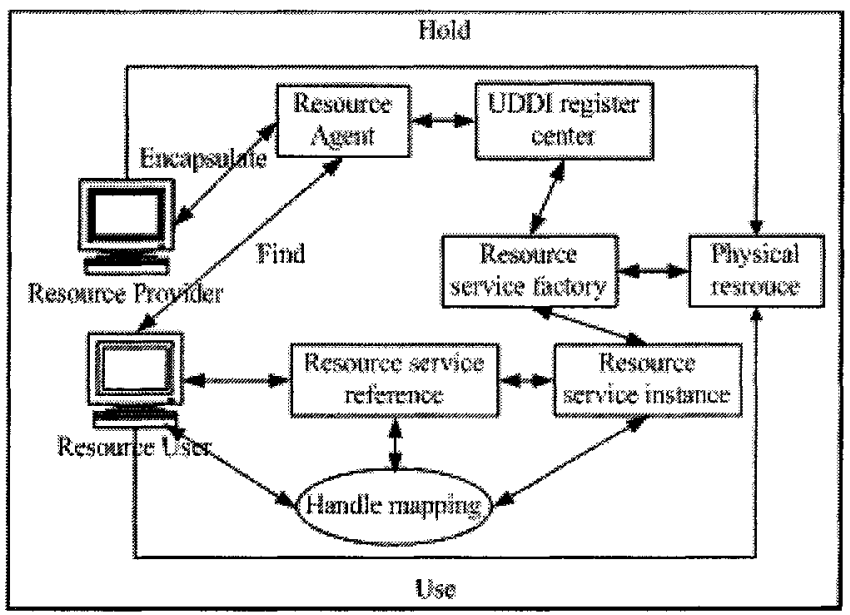

Figure 2. Manufacture grid resource service system 

Grid

\subsection{The structure of resource agent}

The structure of resource agent is shown in Figure 3. It includes perception modular, reaction modular, action modular, decision-making modular, communication modular and knowledge base. Resource agents accepts or queries forwardly the resource request form resource user by perception modular, then send different information to corresponding modular after analysis resource description document. If the perception Information is the simple or urgent, it can be directly delivered to reaction modular which can send the order and movement instruction to the action modular, then the action modular carries out action and gives feedback to the user. Otherwise the information is delivered to the decision-making modular which makes decision by reasoning, then send order and movement instruction to the action modular, the action module carries out the action.

(1) Perception module. It constantly catches external incident request information by perceiving message. Every incident has an identification and the property of beginning time $\mathrm{B}(\mathrm{e})$, termination time $\mathrm{E}(\mathrm{e})$ and occurring period $\mathrm{D}(\mathrm{e})$, the ' $\mathrm{e}$ ' is the name of incident. If resource agent perceives two or many incidents at the same time, it can handle with different method according to the specific condition. The situation includes simultaneity occurring and choice occurring and incorporation occurring, coterminous occurring and nothing occurring etc.

(2) Reaction module. When agent needs to make rapid response to urgent or simple situation, reaction module will be started. Basically it does not carry on reasoning in the reaction module, but directly maps to action by perceive information.

(3) Decision-making module. Agent usually transmits the information from perception information to the decision-making module except the urgent or simple situation. When decision-making module receives it, firstly it carries out information matching retrieval from knowledge library, then uses the reasoning mechanism to infer the information, finally transmit the action order produced from inference to action module.

(4) Action module. Action module carries out some kind of motion based on instruction of reaction module and decision -making module.

(5) Communication module. Agent transmits the information through communication module among themselves..

(6) Knowledge library. There are two kind of knowledge in knowledge library. One is the rule, another is the knowledge block. Knowledge in the knowledge library is the foundation of making decision. The knowledge in the knowledge library is difference based on agent function. 


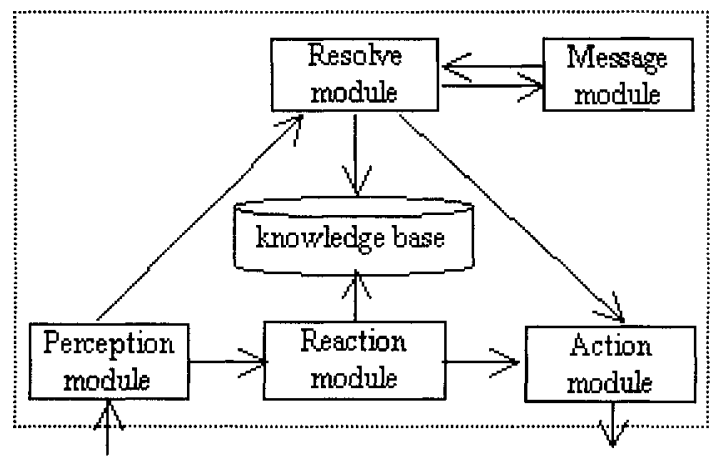

Figure3. The structure of resource agent

\section{MANUFACTURE RESOURCE ENCAPSULATION}

\subsection{Web Services and WSDL standard}

Web Service is a software application which can be recognized by URI(Universal resource identification). Its interface and binding can be described and discovered by XML (eXtensible Markup Language). It can communicate with other software application based on XML information by protocol based on the Internet. WSDL (Web Service Description Language) standard is a criterion to realize the Web Service. WSDL can be used to register and discover the description of interface definition and terminal realization, as well as dynamically produce proxy based on specific interface. WSDL supports dynamical discovery and organization of service in the heterogeneous dynamical grid environment through the standard mechanism which separates definition of interface and specific binding.

\subsection{Description and encapsulation of manufacture resource}

Using WSDL standard to describe and encapsulate manufacture resources usually includes two steps:

Abstract static attribute and dynamic attribute from the manufacture resource, and describe them as service data. It needs to provide a universal standard for attribute definition. Service description will not have misunderstanding between service and user, it also provides safeguard for service querying and discovering. The definition of HUAZHONG NC Machine tool CK6132/750 is shown in Figure 4. NC Machine_CK6132/750 is used to represent equipment resource of NC Machine tool in the XML 

Grid

code, and it can not represent other manufacture resources. The manufacture resources semantics dictionary provides the universal standard for manufacture resource description.

According to manufacture resource semantics dictionary, static attribute and dynamic attribute of each kind of equipment or software application can be ascertained. Static attribute includes equipment name, equipment type, machining size, machining accuracy, document format etc. Dynamic attribute includes machining charge, current equipment working condition, task completion percentage etc. The attribute of HUAZHONG NC Lathe resource is described in Figure 4.

2) Abstract service interface and operation, then describes it as WSDL document, and realize interface. WSDL standard is used to describe interface of manufacture resource service, including the definition of interface type, operation, information, port and related service by referring to naming standard of interface in manufacture resource semantics dictionary. After the WSDL document is defined, the WSDL2Java method can be used to map the WSDL document into a Java file, and interface, operation, binding is realized in Java, and then is compiled into class file.

\section{THE DEVELOPMENT AND CASE OF MANUFACTURE GRID SYSTEM}

At present most of domestic and foreign grid projects are developed on the basis of GT3 (Globus toolkit 3.0), GT3 ${ }^{6}$ is a toolkit which can be used to develop the grid application. We construct the manufacture grid in the Windows 2000 operating systems platform. At present in the GT3 toolkit, only GT3 Core may be installed in the Windows platform. In order to construct manufacture grid by using GT3, firstly some supports tool including J2SE1.3.1, Jakarta ant 1.5.2 and Gt3-core-src.tar must be installed, these tools can be downloaded from correlative java website.

GT3 programming is based on distributed computing programming model, also is called proxy-stub mode, It includes service end programming and customer end programming. The service end and customer end is loosely-coupled, their relation is completed through the WSDL service description document. Manufacture resource service provider must provide the related WSDL service description document when develop service. Service interface, method of transferring service and binding condition of transferring service and the bottom layer communication agreement is describe in the document. After the manufacture resource service user obtained WSDL service description document, the stub of transferring service will be produced according to WSDL document, then transfer the 
service through this stub. The manufacture resource provider may provide many kinds of methods in which transferring service binding with the bottom layer communication agreement. The customer end may choose one kind of methods to transfer service.

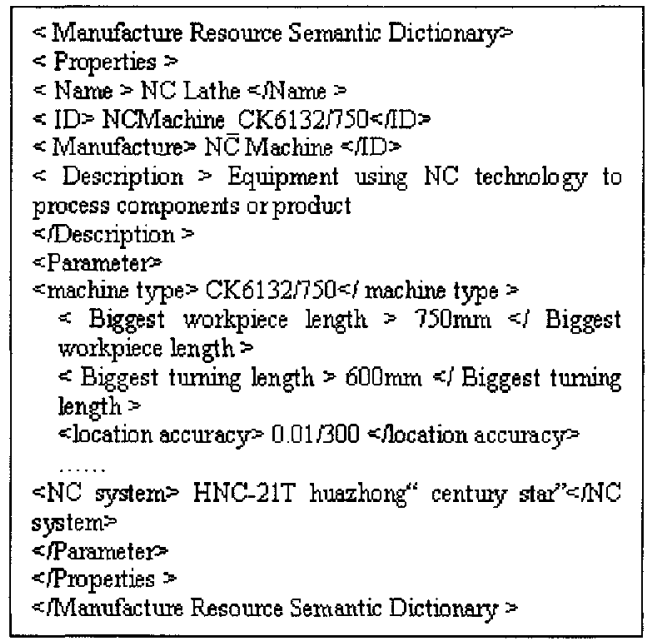

Figure 4. The definition of HUAZHONG NC Lathe

As a case, an automobile steering gear enterprise needs to develop some series of steering gear products, but they developed product mainly by using two-dimensional CAD before. Presently they need to establish the threedimensional CAD product model, and analyze the stress of steering gear. But they do not want to purchase the expensive three dimensional CAD systems and finite element analysis software for the moment. Therefore the enterprise plans to develop this product using the manufacture resources of manufacture grid system. The description of using sharing resources in the manufacture grid system to design and manufacture the steering screw of circulating ball-type steering gear is as follows:

(1) Designers login the manufacture grid system under the authorized situation using unified Web browser interface, and search the CAD software and collaborative design tool in the manufacture grid system, then they carry out the product collaborative design and the craft collaborative design under the support of these tools.

(2) Corresponding initial condition, machining request, dispatching path and address of aimed mainframe is inputted according to machining task demand. The initial condition and the parameter are got from threedimensional product model in the local or the long-distance database, or are obtained through visiting local document. The NC code can be produced by 

Grid

using CAM software automatically. After inspection is finished, if the needed equipment is free, machining code can be transmitted to the aimed computer through clicking the submit button based on the manufacture grid dispatch mechanism. The corresponding encapsulation task will be dispatched to the aimed computer.

(3)The aimed computer server receives dispatched encapsulation task, and analyzes its NC code, then directly transmits it to the local NC machining equipment to carry on the machining process, In the course of process, user may query machining condition of equipments through transmitting inquiry instruction.

(4)The PDM provided by the manufacture grid system will manage all product data in the design and manufacture process.

(5)After the mission is finished, the enterprise will pay for the submitting task through the manufacture grid balance system

The process interface of resources Packaging, resources searching and resources searching transferring is shown in the Figure 5 for PDM software WinCAN of manufacture grid. Encapsulation and transferring process of other software resources and $\mathrm{NC}$ equipments is similar to this. Some models of HUAZHONG NC lathe of CK series and $\mathrm{NC}$ milling machine of YHM series have already been realized sharing in this manufacture grid platform.

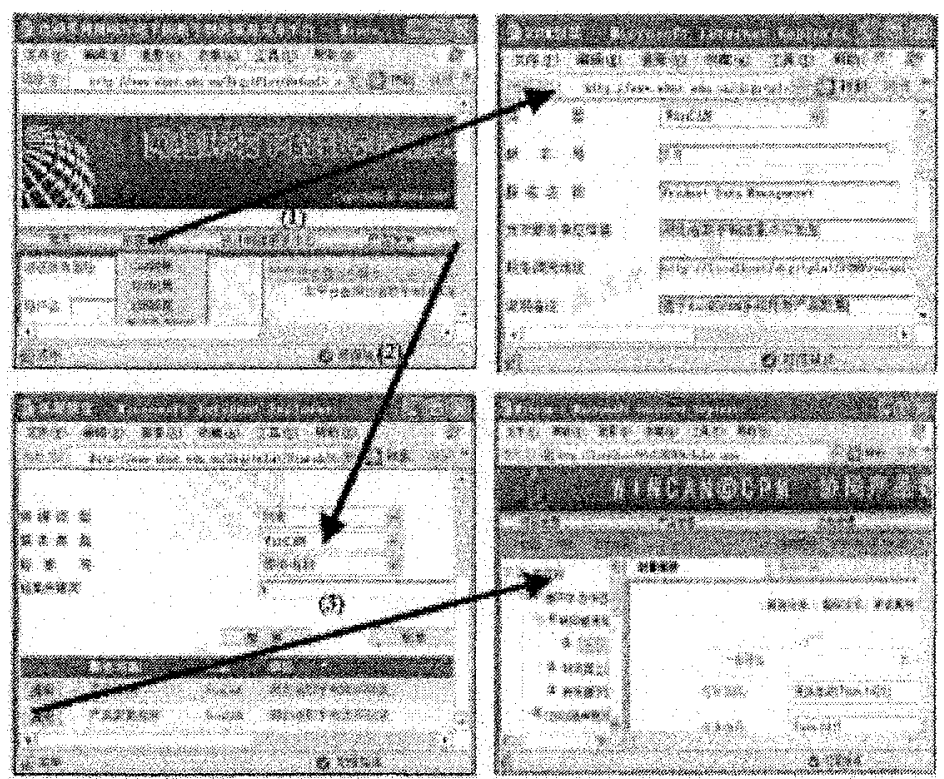

(1) resounce Fackging (2)resource secrching (3)resource trangfeming

Figure 5. PDM software in the Manufacture grid platform 


\section{CONCLUSION}

The solution of constructing manufacture grid system of automobile parts industry is put forward through applying the grid technology into automobile parts industry, and solves the resources sharing question in automobile parts industry on the basis of analyzing the shortage of traditional manufacture resources sharing solution. With unceasing maturating of grid technology research and thorough applying in manufacture domain, it is possible to construct sharing platform of manufacture grid resources facing industry application. With the aid of grid technology's superiority, and through constructing the sharing platform of manufacture grid resources, it may fully meet each kind of manufacture resources sharing need among the virtual enterprises, thus provide a new solution way of manufacture resources sharing among manufacture enterprises.

\section{REFERENCES}

1. I. Foster, C. Kesselman, S.Tuecke(2001), The anatomy of the grid. Intl. Jour. Supercomputer Applications, 15, vol.3,pp.1-21.

2. I. Foster, C. Kesselman, J. Nick et al(2002), The physiology of the grid: an open grid services architecture for distributed systems integration, [EB/OL]. http://www.globus.org/ research/papers/ogsa.pdf

3. Zhang Qing, Fan Yu-shun(2003), Grid Technology and Its Application in Manufacturing. Aeronautical Manufacturing Technology, 2, pp.32-37.

4. Zhou Guang-hui, Jiang Ping-yu(2002),Encapsulation and Integration for Networked Manufacturing Resources Based on Mobile Agents. Computer Integrated Manufacturing Systems, 9, pp.28-32

5. Yang Jing-quan, Dai Ya-fei, Li Wei-gang(1998), Fang Bing-xing. Encapsulation technology of Computing resources web issuing". Computer Engineering and Applications, 1998, 4, pp.52-54.

6. http://www.globus.org/[ EB/OL], Globus Project official website 